\title{
Human and Business Success Factors for Transmedia Design Collaborations
}

\author{
Kevyn Eva Norton and Michelle Helena Kovacs ${ }^{1}$ \\ NHTV BREDA UNIVERSITY OF APPLIED SCIENCES AND \\ NORTONCONCEPTS
}

kevyneva [AT] nortonconcepts.com and kovacs.m [AT] nhtv.nl

\begin{abstract}
:
Audiences expect ever deeper and more immersive media experiences. Producers in film, television, marketing, branding, and journalism are continuously experimenting with telling stories across different media. Transmedia as a term might not be hyped as it was a few years ago, and yet the practice is continuing to grow. Transmedia collaborations across organizations with different media specializations and very different working cultures and techniques are complex. No standards or widely adopted methods have yet evolved that support predictability of cost and return on investment for most projects. While many scholars attend to questions about audience engagement, distributed narratives, and immersive storyworlds, less attention has been given to the interpersonal and interorganizational dimensions of transmedia collaborations. This research combines a literature review and analysis of eleven interviews with Transmedia producers from different media specializations in Europe. Practitioners recommend the practice focuses on the creation of business and measurements models, methods for co-creation, promotion of a transmedia culture, and personal interactions on such projects, rather than on standards and procedures to follow. The findings underline the need for further cross-industry research that investigates not only how audiences experience media but also the media production practices that create those experiences.
\end{abstract}

Keywords: Transmedia, Collaboration, Business Models, Co-creation 


\section{Introduction}

Constant media consumption has become mainstream across all age groups. Today's audiences are in a position to access the content they want anytime, anywhere, and on the device of their choice, often simultaneously using more than one media. Serving audience needs across multiple channels requires creators to produce new media experiences. Transmedia storytelling is the technique of narrating stories across varying platforms, spreading the narrative across the different formats, and uncovering only parts of the story and storyworld in each media. Audiences can choose to consume, interact with, or participate in only a part of the story in a single media, but have the most rewarding experience if they engage across platforms and experience all the pieces as a whole. ${ }^{2}$

Entertainment industry actors recognize the market potential of transmedia. For instance, the leading industry conference around media convergence, South by South West (SXSW), aims to foster networking and learning across different media industries and erode barriers which have traditionally separated the creative, music, film, and interactive industries. ${ }^{3}$ In addition, the leading technology analyst, Gartner Inc., placed transmedia storytelling on the rise curve of its Hype Cycle for Consumer Services and Mobile Applications in 2014. ${ }^{4}$ Although the term transmedia is not as hyped as it was a few years ago, practitioners such as Robert Kirkman from Skybound, creator of the Walking Dead comics, or Jeff Gomez, founder of entertainment company Starlight Runner, continue to reference it in their writings.

Examples such as Harry Potter and Star Wars indicate how a single core narrative can be expanded across multiple media into a multimillion euro franchise. ${ }^{5}$ Trying to tap into this potential, broadcasters in Europe have launched smaller flagship transmedia projects in the past ten years. Unfortunately, many of those projects lacked evidence of a clear return on investment, though audience engagement and brand perception were easily created. At the same time, both practitioners and academics have questioned transmedia's sustainability. ${ }^{6}$ Now that the "buzz" has quieted down, the entertainment industry is working to figure out how to best deliver this narrative form to audiences, motivating them to pay for content while serving the story's creative intentions. ${ }^{7}$

Transmedia projects require a high degree of collaboration among people with a broad set of skills. These people frequently work in different organizations or organizational units; use different design and production techniques, as well as different vocabularies; adhere to different production rhythms; and thrive in different work cultures. In addition, each storytelling experience is unique and requires the contributing media specialists to rethink their approach for each project. In other words, the new formula is no formula. ${ }^{8}$ At the same time, speed and profitability are key to succeed in the fast-moving market of entertainment. It is also important for large media companies to learn to collaborate with smaller, more agile companies in the transmedia sector to achieve the flexibility needed to innovate and produce in a cost-effective manner. ${ }^{9}$

In the context of these complexities, how do organizations and individuals working in transmedia projects ensure financial success while also creating coherent and enjoyable experiences for audiences? This research investigates how producers in Europe from different media backgrounds and from media organizations of different sizes collaborate across 
institutions. It then analyzes which aspects of those collaborations have facilitated success and which aspects generated significant challenges. It identifies key criteria around business models, financial transparency, intellectual property, and new work routines, including the adoption of a "transmedia mindset," as essential benchmarks for the sustainable success of future transmedia projects and the continuous innovation of transmedia design practices.

The tension within transmedia design and production as a still-growing creative and business opportunity and the persistent difficulties it faces as a viable business model in Europe underline the relevance of this research. In addition, the flow of public funds into the transmedia sector-for example, the Convergence of Arts and Information and Communications Technology (ICT) is part of the Digital Agenda for Europe ${ }^{10}$-makes it especially important to engage with questions about best practices to ensure optimal use of funds and avoid potential pitfalls. Identifying success factors from recent transmedia design experiences also helps determine what practitioners perceive as most needed to increase a project's financial viability and deliver a quality experience to audiences.

As the media and entertainment industries contend with profound transformations in audience behaviors and with the rapid emergence of new technologies, understanding "how" people collaborate and interact in the context of transmedia production draws attention to the ways in which practitioners negotiate constant change and disruption in their work worlds. Such research establishes a critical framework to extend and strengthen the existing body of knowledge around transmedia design and production practices. While many scholars attend to questions about audience engagement, distributed narratives, and immersive storyworlds, less attention has been given to the interpersonal and interorganizational dimensions of transmedia collaborations. This gap is addressed here from the perspective of media production practices and methods, focusing on the human dimension of interpersonal and interorganizational collaboration in the media industry in Europe. The findings underline the need for further cross-industry research that investigates not only how audiences experience media but also the media production practices that create those experiences.

\section{Transmedia Production and Design}

Scholarly articles on transmedia production and design commonly reference three core principles defining transmedia: distribution of the narrative across multiple media, creation of a storyworld, and facilitation of audience participation. ${ }^{11}$ These characteristics drive very specific design decisions during the creative process with different impacts upon the various organizations collaborating on the project. These include decisions around the narrative, technology, and business model, ${ }^{12}$ as well as decisions around characters, storyworld, aesthetics, audience engagement, and legal frameworks. ${ }^{13}$ All parties involved in the design and production process-ad agencies, online producers, licensees, and others-need to understand the core voice of the brand, the core rules of the storyworld, and the core narrative, among other variables, to create a satisfying, coherent, and consistent experience for the user. ${ }^{14}$

Managing co-creation among such disparate stakeholders from different media specialties is acknowledged as a key complexity in the transmedia design process. ${ }^{15}$ It requires managers to maintain an overall understanding of how the storyworld and narrative function across 
different media, while also ensuring that contributions from each distinct component of the experience make sense individually. Thus, they must take into account what each media specialist needs to deliver as their part of the design within the specific constraints of particular media platforms and formats. The challenge, of course, is to facilitate a process of co-creation that allows individual stakeholders to reach their specific goals around creativity, commerce, content, and connectivity without jeopardizing the overall coherency of the storyworld and narrative. The professionals interviewed for this research all spoke about projects for which they were responsible for ensuring a common and collective understanding of the overall storyworld existed among the various stakeholders involved in the design and production process. Professional titles vary from showrunners, story architects, continuity managers, or simply transmedia producers ${ }^{16}$ to more hybrid roles, such as the writer-producer or writer-director. ${ }^{17}$

The transmedia maturity in the United States and Europe varies. In the large market of the United States, two distinct kinds of transmedia players are monetizing the internet. In the United States, there are the transmedia producers and digital marketing gurus, such as Starlight Runner Entertainment, 42 Entertainment, and Campfire, as well as the multichannel networks (MCNs) such as Fullscreen, Maker Studios, and Machinima. ${ }^{18}$ In the more fragmented market of Europe, there is noticeable growth in the independent sector, consisting of niche transmedia-oriented agencies, producers, production studios, and technology providers. This trend is likely because smaller firms are more nimble and thus able to adapt to change at a pace larger organizations find difficult. ${ }^{19}$ Young independent companies are designing overall experiences with an iterative evolution in mind, first building audience relations in a digital channel and establishing their value this way. Opting to first design and produce something independently, releasing it in a digital channel, and then getting noticed by the more established media can be a means to secure investment into further building the transmedia franchise. ${ }^{20}$ In addition to specialized transmedia organizations, traditional public relations, marketing, and advertising agencies are entering the transmedia marketplace. ${ }^{21}$ Offshore companies that provide services in media and entertainment production are increasingly engaged in transmedia work as well. ${ }^{22}$

The digital transformation of the media industry not only facilitates the entry of new players into the transmedia sector but also facilitates new models around financing, pricing, sales, and distribution, many of which are built around different levels of user participation and social-networking strategies to supplement more traditional advertising or subscriptionbased models. The increasing role audiences can play in the creation of media experiences, as "prosumers," furthermore requires close attention to how intellectual property rights are managed. ${ }^{23}$

\section{Method}

This research had a cross-sectional qualitative approach, with in-depth interviews of transmedia producers from different types of media organizations. ${ }^{24}$ The exploratory and descriptive purpose was to identify common patterns or themes in how transmedia producers describe their personal experiences in transmedia design through short narratives. ${ }^{25}$ 
The sample was selected through the methods of purposeful selection and conveniencebased selection. ${ }^{26}$ The researcher used a combined approach to achieve the required number of interviews achieving theoretical saturation. ${ }^{27}$

The criteria for selection of the research participants were that they should

- have deep practical expertise in designing transmedia experiences to ensure direct accounts of their experiences could flow into the interviews;

- have played the role of transmedia producers to collect experience accounts which cover the overall production, not the production of a specific media experience;

- have contributed to European transmedia experience designs, where the story is told across at least three different media, to ensure the projects talked about have a distinct level of complexity in their interorganizational collaboration; and

- have come from a variety of media backgrounds, that is, television (TV), film, online/ digital, game, events, print, and technology, to capture the accounts of collaborations from different perspectives.

The author developed an interview guide with six key topics as data collection instrument. To capture the narrative of the transmedia collaborations, the initial questions were focused on team setup, decision making, tools, collaboration success factors and challenges, and audience engagement. The interview guide was lightly adapted before each interview based on the outcome of prior interviews. ${ }^{28}$ The data collection was conducted through phone or Skype interviews of thirty- to seventy-minute durations. Coding and thematic analysis was chosen over qualitative data analysis due to the broad and rather open research question, which focuses more on the "how" of collaboration rather than on a causal analysis question. ${ }^{29}$

The approach for reliability and validity that the author chose for this research aimed to ensure trustworthiness not only at the end of the process but to integrate it into the research process. ${ }^{30}$ The ethical considerations made for this research aimed to comply with the principles of no harm to participants, informed consent, no invasion of privacy, and no deception. ${ }^{31}$

\section{Analysis and Discussion of Data}

Each of the interviewees has been active in transmedia in the past three to twelve years. Their age range is between twenty-eight and fifty, and they are from Belgium, Germany, Portugal, Switzerland, the Netherlands, and the United Kingdom. They are from a variety of organization sizes, ranging between two and more than two thousand employees. They work in public broadcasting, digital agencies, or in specialized studios, which focus on games, apps, or transmedia as a whole. Of the eleven interviewees, six play a hybrid role of CEO, producer, or game designer. For ease of reading, the quotes will be attributed to the interviewees using a code from I-1 to I-11. 
During the interviews, the producers were asked to describe a specific transmedia production where they collaborated with other organizations. They were also asked to describe their experience, specifically around how the project was initiated, how the team was built, what drove success, what caused friction, and how design decisions were taken.

The transmedia experiences the interviewees chose to discuss range from organic transmedia to transmedia brand extensions and span experiences across TV, radio, online, apps, events, and games.

Four key themes emerged from the analysis of the transcripts: funding and project initiation, modes of making decisions, flexibility and continuous adaptation, and tools and collaboration standards. Each of the four themes will be discussed in the following sections.

\section{Funding and Project Initiation}

Showing the value to the commissioning clients and securing funding during project initiation is described as a key success factor in the very early phases of design. The project narratives of interviewees from the public sector illustrated the structured process that needs to be followed to secure a budget. The private sector accounts placed an emphasis on the interpersonal encounters that take place in the build up to a project's initiation. These were encounters at conferences such as "SXSW" and "Power to the Pixel" or within personal business networks. The private sector narratives also identified having a clear user need for the project as a key success factor.

Among the projects discussed during the interviews, financial returns came from a variety of sources: public broadcasters, media rights, app sales, festival entries, and merchandising sales. Whereas a multiyear deal for a television format offers studios a clear model for determining costs and revenue, interviewees identified the lack of viable business models in the transmedia sector as a significant impediment, making it difficult to provide clients with a clear financial picture before the design process commences. In many cases, transmedia producers must break down the design process before a commission to identify costs for the client, which often results in a large amount of unpaid design work:

So of course, the clock is ticking-the TV show is going to go live whatever happens. So, what we want to do to have the clock kicking and get the revenue flowing and they of course did not want to sign off the work before they are comfortable with the concept-so there is a lot of design work we do "free of charge" ... So, we thought we had a good idea and we spent about two months discussing with them the concepts. (I-4)

This phenomenon is similarly acknowledged in broader discussions about the diminished security of media workers in the private creative sector ${ }^{32}$ and can be seen as a key factor that shapes the conditions under which transmedia practices manifest.

As a way to contain some of the risks associated with the lack of upfront spending and absence of standard business models, the interviewees cited a few alternative financial models to help offset the sector's uncertainties. Attempts to derive financial value from every single component of a transmedia project are reflected in the Nanostudio model, for example, where sustainability is attributed to an iterative evolution of a transmedia franchise in 
which revenue from one phase is used to fund subsequent phases. ${ }^{33}$ Another strategy commonly referenced in the research interviews was to re-package the technical platforms developed for specific transmedia projects into a suite of products that transmedia producers can sell to new clients for different story implementations.

Still, the interviewees collectively called for more explicit measurement systems, greater transparency on successes and failures, and new ways of sharing intellectual property rights. If transmedia production is considered a strategy that media companies must embrace for future growth, ${ }^{34}$ more transparent calculations are necessary to meaningfully illustrate a correlation between experience design, customer loyalty, and sales. For some interviewees, this concern was expressed as the need for clearer objectives with respect to client needs and deliverables:

The client has to set clear and unavoidable KPIs (key performance indicators)-so what's the real thing we want to achieve and why? For example: more visitors/more revenue/more commitment/ user details. In terms of agile-thinking: what are we developing for whom? And what is the business value of every single component? (I-2)

Yet, other scholars have documented that data in the transmedia sector are often padded, or viewed through "rosy glasses." 35 Interviewees affirmed this lack of transparency, noting a general distrust of data reporting and a lack of meaningful discussions about factors contributing to a project's success or failure. In particular, the interviewees attribute this tension to the pressure producers feel to demonstrate success for clients and their brands, which inhibits a more open and frank conversation about the generation of real value that might help advance the practice, as the following quote makes clear:

What I'd wish for others is to be much more transparent about the success and failures, and about exactly how many people use this website, and how many they expected to use it. Because I think at the moment, really have no idea how successful these things are, how much they cost, whether it's good value for money ... I know for a fact, actually, that a lot of companies have lied about how successful their project was. How are we supposed to learn with people just lying about how successful their stuff was? (I-3)

An additional challenge to improved profitability in the transmedia sector centers on intellectual property, especially questions of ownership when private production companies create content for public broadcasters.

Sherlock Holmes is a good example. So, the new BBC show, Sherlock Holmes. . . . The production company retained the digital rights so that meant when they got approached by the Project Factory to make an app, they can keep all the upside to that revenue. So, you want more production companies like that that are thinking: "Actually, I could be the owner of an entertainment franchise and I'm not just a TV company," because then they would be more inclined to invest in those other components. (I-4)

As long as transmedia producers remain alienated from the intellectual property they create for others, their ability to exploit that content for their own financial gains remains limited or unobtainable with only few exceptions. ${ }^{36}$ 


\section{Decision Making}

The second theme that emerged from the interviews focused on decision-making processes. Interviewees repeatedly attributed success to having the right people together in the right place at the right time. Transmedia practitioners make a multitude of decisions during the design stages that influence the economic, creative, and industrial aspects of a transmedia project. ${ }^{37}$ The infinite options can overwhelm practitioners and thus require transmedia producers to master effective delegation. ${ }^{38}$ Actively working together in a shared physical space makes this process much more productive.

In addition, making decisions in a co-creative manner was favored by all interviewees and was considered necessary for building innovative and engaging user experiences, a find that has been underscored by academic literature. ${ }^{39}$ However, not all stakeholders share the same enthusiasm for co-creation. Interviewees acknowledged hesitance among some of their clients who struggled to collaborate with transmedia producers, fearing they might lose too much control over their ideas if they welcomed transmedia producers as co-creators or co-authors. A strong separation between teams who come up with ideas and teams who execute those ideas across media platforms was considered limiting by many transmedia producers interviewed for this research:

The most frustrating thing is that they all didn't really kind of believe in what we were doing. So that's kind of a frustration. They just made plans and didn't really talk to us about their decisions. We always came last in the decision-making process. (I-1)

As mentioned previously, all interviewees put a strong emphasis on the positive benefits that result from sharing the same physical space with collaborators during the creation process, especially because it puts professionals with different media specializations into the same room during crucial moments of strategic decision making. Communicating with colleagues who have different areas of expertise helps practitioners avoid misunderstandings and increases their effectiveness when they retreat to their respective media organizations or organizational units to complete their individual contributions to the overall project. The following quote illustrates the importance of co-location to the decision-making process:

For the type of work we do, and most of our work is international and involves teams sometimes in different countries, it's not very easy. But, for me, what is really important is these brainstorm moments where people get together, have ideas, try to improve that idea and try to create something new. (I-11)

The key factor, thus, is to know when to have people to get together and co-create, but also when to have people dive into their specialty, to allow them to achieve the design depth needed for a comprehensive experience. Knowing how to balance these working modes is a key competence of the show runner or transmedia producer.

When asked about co-location with clients, opinions varied. Some projects had great experiences with clients on site, while other projects did not have the client on site and stated that they prefer it that way. Academic articles about project collaborations all focus on contexts in which collaborators worked together at the same site and thus mirror the importance of 
co-location in the creative process. ${ }^{40}$ One interviewee expanded on the co-location theme to say his company plans to co-locate a network of creative companies in the style of a technology park or creative clusters.

Audience participation in the decision process is a topic that divides the interviewees. Some do it only if ordered so by the client, while others feel that audience interaction in the design process is a key to success and a desirable attribute of transmedia work more generally. The following quote illustrates this issue:

So what I like is the fact that you could do something in the morning and you can see the results in the afternoon. That's the way we started Sofia's Diary. Basically, we were creating the story as we go and that immediate feedback from the audience allowed us to, I believe, be better writers and be better at creating. (I-11)

In contrast to this love for audience interaction and engagement is a clear antipathy to the practice, as the following interview comment reflects: "No, we normally don't do it unless someone makes us do it" (I-3).

\section{Being Flexible and Continuously Adapting}

Dealing with unexplored or novel media combinations and constantly innovating new work flows and creative outputs require high capacity to deal with uncertainty. The interviewees consistently emphasized the need for transmedia practitioners to maintain high degrees of flexibility during the design and production phases. When interviewees described their professional roles, they offered little consistency in their job titles, variously calling themselves producer, game producer, show runner, television producer, curator, generic concept maker, and story architect. Nevertheless, a common theme in their responses was the fundamental diversity of what the job requires of them, often asking them to wear multiple hats at the same time. The way interviewees describe their work corresponds to the recognition that hybrid roles such as the writer-producer, writer executive producer, writer-director, and writer-producer-director ${ }^{41}$ are increasingly common, which has been acknowledged in other accounts of work in the digital sector. ${ }^{42}$

The ability for individuals to step away from sole control over a project and learn to adapt to a more collaborative approach to design and production represents a certain mind-set that the interviewees identified as key for success. The importance of listening to each other and being able to understand and adopt each other's methods and vocabularies is more important than to prescribe a defined method or process, which was perceived as an unnecessary limitation upon the skill and creativity of the different individuals participating in the same project. This approach was described as a "transmedia mindset," and widely recognized as a critical element needed to advance transmedia practice and media work more generally in an increasingly convergent industry. ${ }^{43}$ For example,

The key challenge up to today is culture. They are all journalists working for the same media house but two cultures are obvious. . . . Cultures manifest that there are different ways to tell a story according to the different vectors. That was a challenge with "Jede Rappe Zählt" to find each other on the level of depth-what gets told, what does not get told. (I-9) 
This flexibility is seen not only on an individual level but also on an organizational level. The interviewees describe a dynamic environment in terms of how their companies have evolved over the past four years. This dynamic was reflected in one of three ways: a move to increased specialization, an expansion of scope of work, or in a strategic re-organization. The move to specialization is illustrated by the case of Spektor, who moved away from being a full-service agency to being storytelling specialists within a network of creative agencies. This mirrors the idea of narrative-centric production. ${ }^{44}$ In the other direction is the evolution to increase the scope of the organizational activities which beActive displays. At the center of the organizational change is the integration of additional competencies, such as marketing and distribution, to gain full control of the value chain and the commercial aspects of projects. In the case of the Festival Producer, the move is one to a broader entertainment brand organization, enabling the expansion of the story being told, not only during the festival but also before and after, allowing the expansion of the story into more varied media experiences to reach a larger audience.

At the core of the Swiss public broadcaster's strategy stands the idea that any story needs to be told across three core channels: TV, radio, and internet. This take on the new audience experience is reflected in the new organization structure implemented in 2012. SRF (Schweizer Radio und Fernsehen) organized around seven departments that each have responsibilities across all the three vectors-TV, radio, and online. Any project submitted within or to the SRF now needs to follow a three-vector strategy to be considered for execution. The idea is not only to replicate content across channels but also to expand the audience experience through distinct elements in each media. This change in organizational structure reflects a new production model that is inherently built to create transmedia content. The picture portrayed of public broadcasters in literature is a more static one, with the organizations still largely organized around media silos. ${ }^{45}$ The change in organization strategy and continuous adaptation not only on an individual level but also on an organizational level reflects the agility required to survive in the converged media industry. ${ }^{46}$

\section{Tools and Collaboration Standards}

The interviewees spoke at length about the business and human aspects of the collaborative and creative process and what tools best enabled them to do their jobs successfully. Professional tools frequently cited in the interviews include iPhone, GoogleDocs, Dropbox, Skype, Word Documents, spreadsheets, and presentations. The early concept documentation was characterized as a series of short written documents, potentially with pictures, but more often text-heavy. Consistently communicating is seen more critical to project success than documenting:

You cannot run a business saying "here you have a document and now run with it". Maybe that works like in old style companies-in our company evaluation is very important all the time. That's why this personal contact and skype and phone calls for everyone all the time is how we work. (I-6).

Indeed, some interviewees detailed the challenging negotiations that occur as part of large creative teams on how to best advance a project, signaling the need for clear, direct, and written instructions as a necessary mechanism to save time and avoid misunderstandings. 
Others, however, mirror the preferences of software developers and other high-tech work cultures, opting for a more agile approach to production in which teams are co-located with frequent face-to-face interactions with the client. Literature also identifies the growing adoption of agile work routines from the online and digital sectors within the media and entertainment industry. ${ }^{47}$

\section{Conclusion}

The objective of this research was twofold: to understand the success factors transmedia producers in Europe perceive as key in the collaboration between different organizations during a transmedia design and to analyze which elements would benefit further development of a transmedia practice. Interviewees identified human factors as most important for a successful collaboration: openness, flexibility, and willingness to deconstruct one's own work and remix these outputs with contributions from others. Key moments during the design process were said to be sessions of co-creation, where people from the different domains work together in the same room.

The transmedia collaborations described in this research are the combination of artistic endeavors around storytelling, user experience design, and problem solving through technology. Such collaborations bring together very distinct skill sets and approaches across a range of professionals with diverse media experiences. The practitioners described a positive correlation between the quality of the transmedia project and the amount of interaction between specialists with different expertise and backgrounds. Analysis of the practitioner interviews and existing academic literature leads to a conclusion that key focus for further development of the practice should be in the area of co-creation. A further conclusion from the interviews that contrasts with existing literature is the de-prioritization of the setting of standards and vocabularies. Instead, interviewees believed face-to-face communication was more productive. Speaking more to each other in the design process more easily dissolved conceptual misunderstandings and differing vocabularies.

Methods from the technology sector have made their way into transmedia practices. The structured and logical dimension of technology projects fits well with the need for complex orchestration, coordination, and interfacing between different media technologies and practitioners. Likewise, agile methods from the technology sector have helped facilitate more productive collaborations across these differences. However, to fully develop the potential of the practice from the storytelling point of view, these methods would need to integrate the design needs of the cognitive and emotional journey of the Viewer User Player. The challenge for the practice is to further rationalize design and production to achieve cost predictability and efficiency, but at the same time manage to shift the focus away from technological complexity and software development to the storytelling and human aspects of the projects.

A second strong theme to emerge from the interviews was the apparent lack of viable business models and underdeveloped measurement systems to make contributing factors to success and failure more transparent. As long as there is no transparency on the true return 
on investment beyond unverified anecdotes and questionable data, more robust financial investments in the area will remain unobtainable, and thus, the market will fail to grow. Success factors discussed both in the interviews and in literature to deal with these business issues are to ensure that intellectual property rights are granted to the transmedia producers. The interviewees also emphasized the importance of designing business models into the experiences from the start. For a transmedia business model to succeed, the individual components need to be successful. Indeed, greater revenue and success potential materializes exponentially when components succeed together. Business and partnership models around this principle should drive transmedia design processes and other creative decisions.

Finally, collaborations between public broadcasters and smaller niche agencies illustrated a trend in which complex execution was outsourced from the former to the latter. However, due to the increased maturity of internal departments with transmedia expertise, initial project conception was often carried out within the broadcasters, which is a central difference from accounts in existing literature. Reopening those boundaries could be fruitful for future innovations.

\section{Limitations}

The interviews were not executed consistently; instead, they were carried out with a mix of Skype and voice-only calls and no in-person interviews. No follow-up discussions took place; therefore, the topics identified were the top-of-mind topics at a given point in time. In addition, one final interview with a transmedia branding producer was canceled last minute, and the author did not succeed in scheduling a replacement interview, so the perspective of transmedia branding is underrepresented in the study. This research focused on the perspective of the transmedia producers only, and not on other participants in the collaboration between companies of different media experiences.

\section{Recommendations}

The wide adoption of agile methodologies is an opportunity to build on. The agile methodologies provide a means to deal with the rapidly changing environment and to focus on speed of delivery. Agile's principle of continuous learning fits well with the individual nature of each transmedia project. The agile methods can be expanded to include tests involving writers and psychologists to validate the emotional and cognitive aspects of the experience while it is being created. This can build further understanding around the emotional and psychological mechanisms of media transitions in the Viewer User Player.

The globalization of industries is also a reality for the media industry, with the large media enterprises investigating how work can be performed in regions with lower labor costs. This trend is likely to grow. The strong emphasis which was put on the co-location aspect of creative teams needs to be put in the context of a potential delivery strategy comprising nearor offshoring of work to different geographical regions. Knowing which aspects of the creative process are more effective to perform in a co-located manner and with higher investments, and knowing which to offshore, is key. Along with this, shaping the handovers and the collaboration between the team members in different geographical regions is a key competence to build. 


\section{Suggestions for Further Studies}

Other researchers could investigate this area using different methodologies and including other variables. As some highlights, these studies could

- conduct a study on interorganizational collaboration that adds different perspectives than those of the transmedia producers;

- create a transmedia business model based on complexity assessment of user engagement and return on investment;

- combine the fields of audience or reception studies with transmedia production research to develop recommendations on how to further integrate the emotional and cognitive aspects into the design approach of a transmedia project;

- add new techniques to frameworks that address the flow of user attention and the cognitive and emotional processes that occur when switching between lean forward and lean back viewing experiences;

- analyze whether the findings of these interviews of the producers working in Europe are equally valid (or in what elements they differ) in other geographies/cultures.

${ }^{1}$ Kevyn Eva Norton is a digital transformation and user experience consultant focusing on global corporations and niche publishers. She is currently User Research Advisor for "Shadowsedge," a mobile game for teens to promote journaling and art as ways to build emotional resilience. Michelle Helena Kovacs is Lecturer and Researcher at Breda University of Applied Sciences specializing in consumer behavior.

${ }^{2}$ Henry Jenkins, "The Revenge of the Origami Unicorn: Seven Principles of Transmedia Storytelling (Well, Two Actually. Five More on Friday)," Confessions of an Aca-FanThe Official Weblog of Henry Jenkins, December 12, 2009, http://henryjenkins. org/2009/12/the_revenge_of_the_origami_uni.html (accessed July 12, 2017).

${ }^{3}$ SXSW, "Convergence: The Intersection of Interactive, Film and Music," 2015, http:// www.sxsw.com/convergence/about (accessed May 16, 2015).

${ }^{4}$ Brian Blau, "Hype Cycle for Consumer Services and Mobile Applications," Gartner, July 29, 2014, https://www.gartner.com/doc/2810218/hype-cycle-consumerservices-mobile (accessed May 16, 2015).

${ }^{5}$ Indrek Ibrus and Carlos A. Scolari, "Transmedia Critical: Empirical Investigations into Multiplatform and Collaborative Storytelling," International Journal of Communication 8 (2014): 2191-200.

${ }^{6}$ Dan Franklin, "Despite Promise Transmedia Publishing Is Still Mostly a Mess," Publishing Perspectives, December 2012, http://publishingperspectives.com/ 2012/12/despite-promise-Transmedia-publishing-still-mostly-a-mess / (accessed May 16, 2015).

${ }^{7}$ Melanie Goodfellow, "Get Your Story Right and Know Who You Are Talking To," Power to the Pixel, n.d., http://www.powertothepixel.com/get-your-story-rightand-know-who-youre-talking-to/ (accessed July 12, 2017). 
${ }^{8}$ Nuno Bernardo, The Producer's Guide to Transmedia: How to Develop, Fund, Produce and Distribute Compelling Stories across Multiple Platforms (Lisbon: Beactive Books, 2011), iBooks edition.

${ }^{9}$ Carlos Scolari, "Transmedia Storytelling: New Ways of Communicating in the Digital Age," in AC/E Digital Culture Annual Report 2014 (Madrid: Acción Cultural Española, 2014), 69-78.

${ }^{10}$ European Commission, "Convergence Digital Agenda for Europe," 2015, https:// ec.europa.eu/digital-agenda/en/media-convergence (accessed July 12, 2017).

${ }^{11}$ Mariana Ciancia, "What Is Transmedia? Projects and Thoughts beyond the Buzzword" (paper presented at the 19th International Symposium on Electronic Art, Sydney, Australia, June 11-13, 2013); Mark Deuze, "Media Industries, Work and Life," European Journal of Communication 24 (4, 2009): 467-80; Jenkins, "The Revenge of the Origami Unicorn"; Roberto Rampazzo Gambarato, "Transmedia Project Design: Theoretical and Analytical Considerations," Baltic Screen Media Review 1 (2013): 80-100; Gareth Reece and David Thomas, "Transmedia Convergence: Where's the Audience?" (Lancaster, UK: HighWire D. T. C. Transmedia Convergence, 2011). Scolari, "Transmedia Storytelling"; Andrea Phillips, A Creator's Guide to Transmedia Storytelling: How to Captivate and Engage Audiences across Multiple Platforms (McGraw-Hill Professional, 2012), Kindle edition.

12 Ciancia, "What Is Transmedia."

${ }^{13}$ Bernardo, The Producer's Guide to Transmedia; Christie Dena, "Transmedia Practice: Theorising the Practice of Expressing a Fictional World across Distinct Media and Environments" (PhD diss., University of Sydney, 2010); Rampazzo Gambarato, "Transmedia Project Design"; Robert Pratten, Getting Started in Transmedia Storytelling (London: Talking Objects, 2014), pdf edition.

14 "Transmedia and the Changing Entertainment World," Starlight Runner, last modified September 24, 2013, http://www.starlightrunner.com/Transmedia_And_ The_Changing_Entertainment_World (accessed July 12, 2017).

${ }^{15}$ Deuze, "Media Industries, Work and Life."

${ }^{16}$ Dena, "Transmedia Practice"; Ciancia, "What Is Transmedia"; Phillips, A Creator's Guide to Transmedia Storytelling.

${ }^{17}$ Dena, "Transmedia Practice."

${ }^{18}$ Denise Mann, "Welcome to the Unregulated Wild, Wild, Digital West," Media Industries 1 (2, 2014), http://www.mediaindustriesjournal.org/index.php/mij/ article/view / 47 (accessed July 12, 2017).

${ }^{19}$ Rosa Franquet and Maria Isabel Villa Montoya, "Transmedia Critical| Cross-Media Production in Spain's Public Broadcast RTVE: Innovation, Promotion and Audience Loyalty Strategies," International Journal of Communication 8 (24, 2014): 2301-22. Scolari, "Transmedia Storytelling."

${ }^{20}$ Bernardo, The Producer's Guide to Transmedia; Indrek Ibrus, "AV-Industry's Micro-Companies and Crossmedia Innovation," Acta Academiae Artium Vilnensis 67 (2012): 61-72; Simon McPhillips and Omar Merlo, "Media Convergence and the Evolving Media Business Model: An Overview and Strategic Opportunities," Media Convergence 22 (3, 2013): 237-54.

${ }^{21}$ Burghardt Tenderich, Transmedia Branding, ed. H. Schmidt and J. Schmidt (Nierstein: European Institute for Media Optimization, 2014). 
${ }^{22}$ Deuze, "Media Industries, Work and Life"; Dana Mietzner and Martin Kamprath, "A Competence Portfolio for Professionals in the Creative Industries," Creativity and Innovation Management 22 (3, 2013): 280-94.

${ }^{23}$ Steve Cunningham, "Emergent Innovation through the Coevolution of Informal and Formal Media Economies," Television \& New Media 13 (2012): 415-30.

${ }^{24}$ Alan Bryman, Social Research Methods (NY: Oxford University Press, 2012).

${ }^{25}$ Catherine Marshall and Gretchen B. Rossman, Designing Qualitative Research (Los Angeles: SAGE, 2010).

${ }^{26}$ Bryman, Social Research Methods.

${ }^{27}$ Joseph A. Maxwell, Qualitative Research Design: An Interactive Approach (Los Angeles: SAGE, 2012).

${ }^{28}$ Matthew B. Miles, Michael Huberman, and Johnny Saldaña, Qualitative Data Analysis: A Methods Sourcebook (Los Angeles: SAGE, 2013).

${ }^{29}$ Jochen Gläser and Grit Laudel, "Life with and without Coding: Two Methods for Early-Stage Data Analysis in Qualitative Research Aiming at Causal Explanations," Forum Qualitative Sozialforschung/Forum: Qualitative Social Research 14 (2, 2013), http://www.qualitative-research.net/index.php/fqs/article/view/1886/3528 (accessed July 12, 2017).

${ }^{30}$ Janice M. Morse, Michael Barrett, Maria Mayan, Karin Olson, and Jude Spiers. "Verification Strategies for Establishing Reliability and Validity in Qualitative Research," International Journal of Qualitative Methods 1 (2, 2008): 13-22.

${ }^{31}$ Bryman, Social Research Methods.

${ }^{32}$ Deuze, "Media Industries, Work and Life"; Cecilia Roos, "Producing Transmedia Stories-A Study of Producers, Interactivity and Prosumption" (Master's thesis, Malmö University, 2012).

${ }^{33}$ Nuno Bernardo, Transmedia 2.0 (Lisbon: Beactive Books, 2014), iBooks edition.

${ }^{34}$ Cunningham, "Emergent Innovation"; McPhillips and Merlo, "Media Convergence."

${ }^{35}$ Phillips, A Creator's Guide to Transmedia Storytelling.

${ }^{36}$ Indrek Ibrus and Maarja Ojamaa, "Transmedia Critical| What Is the Cultural Function and Value of European Transmedia Independents?" International Journal of Communication 8 (18, 2014): 2283-300.

${ }^{37}$ Dena, "Transmedia Practice"; Elizabeth Evans, "Transmedia Critical| "We're All a Bunch of Nutters!' The Production Dynamics of Alternate Reality Games," International Journal of Communication 8 (19, 2014): 2323-43.

${ }^{38}$ Roos, "Producing Transmedia Stories."

${ }^{39}$ Ciancia, "What Is Transmedia"; Dena, "Transmedia Practice"; Deuze, "Media Industries, Work and Life"; Roos, "Producing Transmedia Stories."

${ }^{40}$ Evans, "Transmedia Critical"; Geoffrey A. Long, "Transmedia Storytelling: Business, Aesthetics and Production at the Jim Henson Company" (Master's thesis, Massachusetts Institute of Technology, 2007). Andrew David Merkin, "The Management of Transmedia Production in an Era of Media and Digital Convergence" (Master's thesis, Massachusetts Institute of Technology, 2010); Roos, "Producing Transmedia Stories."

41 Dena, "Transmedia Practice."

42 Evans, "Transmedia Critical." 
${ }^{43}$ Ciancia, "What Is Transmedia"; Deuze, "Media Industries, Work and Life"; Ivar John Erdal, "Cross-Media (Re)Production Cultures," Convergence 15 (2, 2009): 215-31; Evans, "Transmedia Critical"; Scolari, "Transmedia Storytelling."

${ }^{44}$ Merkin, "The Management of Transmedia."

${ }^{45}$ Franquet and Montoya, "Transmedia Critical| Cross-Media"; Scolari, "Transmedia Storytelling."

${ }^{46}$ Gracie Lawson-Borders, "More than a Mouse Trap: Effective Business Models in a Digital World," The International Journal on Media Management 12 (1, 2010): 41-45; Scolari, "Transmedia Storytelling."

${ }^{47}$ Ibrus, "AV-Industry's Micro-Companies."

\section{Bibliography}

Bernardo, Nuno. Transmedia 2.0. Lisbon: Beactive Books, 2014. iBooks edition.

Bernardo, Nuno. The Producer's Guide to Transmedia: How to Develop, Fund, Produce and Distribute Compelling Stories across Multiple Platforms. Lisbon: Beactive Books, 2011. iBooks edition.

Blau, Brian. "Hype Cycle for Consumer Services and Mobile Applications." Gartner, July 29, 2014. https://www.gartner.com/doc/2810218/hype-cycle-consumer-servicesmobile (accessed May 16, 2015).

Bryman, Alan. Social Research Methods. New York: Oxford University Press, 2012.

Ciancia, Mariana. "What Is Transmedia? Projects and Thoughts beyond the Buzzword." Paper presented at the 19th International Symposium on Electronic Art, Sydney, Australia, 2013.

Confessions of an Aca-Fan-The Official Weblog of Henry Jenkins. http://henryjenkins.org.

Cunningham, Steve. "Emergent Innovation through the Coevolution of Informal and Formal Media Economies." Television \& New Media (2012): 415-30.

Dena, Christie. "Transmedia Practice: Theorising the Practice of Expressing a Fictional World across Distinct Media and Environments." PhD diss., University of Sydney, 2010.

Deuze, Mark. "Media Industries, Work and Life." European Journal of Communication 24, no. 4 (2009): 467-80.

Erdal, Ivar John. "Cross-Media (Re)Production Cultures." Convergence 15, no. 2 (2009): 215-31.

European Commission. "Convergence Digital Agenda for Europe." Last modified 2015. https://ec.europa.eu/digital-agenda/en/media-convergence.

Evans, Elizabeth. “Transmedia Critical| 'We're All a Bunch of Nutters!' The Production Dynamics of Alternate Reality Games." International Journal of Communication 8, no. 19 (2014): 2323-43.

Franklin, Dan. "Despite Promise Transmedia Publishing Is Still Mostly a Mess." Publishing Perspectives, December, 2012. http://publishingperspectives.com/2012/12/despitepromise-Transmedia-publishing-still-mostly-a-mess /. 
Franquet, Rosa and Maria Isabel Villa Montoya. "Transmedia Critical| Cross-Media Production in Spain's Public Broadcast RTVE: Innovation, Promotion and Audience Loyalty Strategies." International Journal of Communication 8, no. 24 (2014): 2301-22.

Gläser, Jochen and Grit Laudel. "Life with and without Coding: Two Methods for EarlyStage Data Analysis in Qualitative Research Aiming at Causal Explanations." Forum Qualitative Sozialforschung/Forum: Qualitative Social Research 14, no. 2 (2013). http://www.qualitative-research.net/index.php/fqs/article/view/1886/3528.

Goodfellow, Melanie. "Get Your Story Right and Know Who You're Talking To." Power to the Pixel, n.d. http://www.powertothepixel.com/get-your-story-right-and-knowwho-youre-talking-to/.

Ibrus, Indrek. "AV-Industry's Micro-Companies and Crossmedia Innovation." Acta Academiae Artium Vilnensis 67 (2012): 61-72.

Ibrus, Indrek and Carlos A. Scolari. "Transmedia Critical: Empirical Investigations into Multiplatform and Collaborative Storytelling." International Journal of Communication 8, no. 24 (2014): 2191-200.

Ibrus, Indrek and Maarja Ojamaa. "Transmedia Critical| What Is the Cultural Function and Value of European Transmedia Independents?" International Journal of Communication 8, no. 18 (2014): 2283-300.

Lawson-Borders, Gracie. "More than a Mouse Trap: Effective Business Models in a Digital World." The International Journal on Media Management 12, no. 1 (2010): 41-45.

Long, Geoffrey A. "Transmedia Storytelling: Business, Aesthetics and Production at the Jim Henson Company." Master's thesis, Massachusetts Institute of Technology, 2007.

Mann, Denise. "Welcome to the Unregulated Wild, Wild, Digital West." Media Industries 1, no. 2 (2014). http://www.mediaindustriesjournal.org/index.php/mij/article/ view $/ 47$.

Marshall, Catherine and Gretchen B. Rossman. Designing Qualitative Research. Los Angeles: SAGE, 2010.

Maxwell, Joseph A. Qualitative Research Design: An Interactive Approach. Los Angeles: SAGE, 2012.

McPhillips, Simon and Omar Merlo. "Media Convergence and the Evolving Media Business Model: An Overview and Strategic Opportunities." The Marketing Review 8, no. 3 (2008): 237-53.

Merkin, Andrew David. "The Management of Transmedia Production in an Era of Media and Digital Convergence." Master's thesis, Massachusetts Institute of Technology, 2010.

Mietzner, Dana and Martin Kamprath. "A Competence Portfolio for Professionals in the Creative Industries." Creativity and Innovation Management 22, no. 3 (2013): 280-94.

Miles, Matthew B., A. Michael Huberman, and Johnny Saldaña. Qualitative Data Analysis: A Methods Sourcebook. Los Angeles: SAGE, 2013.

Morse, Janice M., Michael Barrett, Maria Mayan, Karin Olson, and Jude Spiers. "Verification Strategies for Establishing Reliability and Validity in Qualitative Research." International Journal of Qualitative Methods 1, no. 2 (2008): 13-22. 
Phillips, Andrea. A Creator's Guide to Transmedia Storytelling: How to Captivate and Engage Audiences across Multiple Platforms. McGraw-Hill Professional, 2012. Kindle edition.

Pratten, Robert. Getting Started in Transmedia Storytelling. Talkingobjects, 2014. PDF edition.

Rampazzo Gambarato, Roberto. "Transmedia Project Design: Theoretical and Analytical Considerations." Baltic Screen Media Review 1 (2013): 80-100.

Reece, Gareth and David Thomas. "Transmedia Convergence: Where's the Audience?" HighWire D. T. C. Transmedia Convergence, 2011.

Roos, Cecilia. "Producing Transmedia Stories-A Study of Producers, Interactivity and Prosumption." Master's thesis, Malmö University, 2012.

Scolari, Carlos. "Transmedia Storytelling: New Ways of Communicating in the Digital Age." In AC/E Digital Culture Annual Report 2014, 69-78. Madrid: Acción Cultural Española, 2014.

Starlight Runner. "Transmedia and the Changing Entertainment World." Last modified September 24, 2013. http://www.starlightrunner.com/Transmedia_And_The_ Changing_Entertainment_World.

SXSW. "Convergence: The Intersection of Interactive, Film and Music." http://www.sxsw .com/convergence/about (accessed May 16, 2015).

Tenderich, Burghardt. Transmedia Branding. Edited by H. Schmidt and J. Schmidt. Nierstein: European Institute for Media Optimization, 2014. PDF edition. 